Hamburg. Nach Promotion 1995, einigen Jahren als Lehrbeauftragte, Rechtsanwältin und Stipendiatin der Deutschen Forschungsgemeinschaft (DFG) und Habilitation 2004 an der Universität Hamburg erhielt sie die Lehrbefugnis für Staatsund Verwaltungsrecht sowie Sozialrecht. Nach Vertretungsprofessuren in Hamburg und Frankfurt wurde sie Professorin für Öffentliches Recht, insbesondere Öffentliches Wirtschaftsund Umweltrecht, an der Helmut-Schmidt-Universität/Univer- sität der Bundeswehr in Hamburg. Sie ist verheiratet und hat zwei Kinder. Von 2008 bis 2011 war sie Mitglied in der Sachverständigenkommission zur Erstellung des Gleichstellungsberichts der Bundesregierung. Margarete Schuler-Harms ist seit 1989 Mitglied des djb und seit 1995 Mitglied der Kommission Recht der sozialen Sicherung, Familienlastenausgleich. Im September 2009 übernahm sie den Vorsitz der Kommission.

\title{
Bewerbungen für den Marie Elisabeth Lüders-Preis 2013
}

Der djb vergibt in Anerkennung hervorragender rechts- oder wirtschaftswissenschaftlicher Arbeiten alle zwei Jahre den Marie Elisabeth Lüders-Preis. Ausgezeichnet werden Rechtsund Wirtschaftswissenschaftlerinnen. Preiswürdig sind rechts- oder wirtschaftswissenschaftliche Dissertationen und Habilitationsschriften zum Bereich Recht und Geschlecht sowie Arbeiten, die im Zusammenhang mit dem Thema Gleichstellung von Frau und Mann deutliche rechts- oder wirtschaftswissenschaftliche Bezüge aufweisen. Die Mit- gliedschaft im djb ist keine Voraussetzung. Der Preis besteht aus einem Druckkostenzuschuss in Höhe von 2.000,- Euro und wird alle zwei Jahre durch die Präsidentin im Rahmen der Mitgliederversammlung verliehen.

Bewerbungen für den Marie Elisabeth Lüders-Preis 2013 sind bis zum 31. August 2012 bei der Präsidentin des djb, Bundesgeschäftsstelle des djb, Anklamer Straße 38, 10115 Berlin einzureichen. Weitere Informationen: http://www.djb.de/ Wissenschaftspreis/Preisordnung/

\section{Geburtstage}

(Januar bis März 2012)

\section{Jahre}

Dr. Elisabeth Hoffmann Rechtsanwältin Brüssel

Marianne Landvogt Richterin am LG i.R. Bonn

\section{Jahre}
Freifrau Hannah von Senden Rechtsanwältin und Notarin Hannover

Dr. Heidi Lambert-Lang
Richterin am BGH i.R.
Zweibrücken

Waltrud Regine Schneider-Danwitz Verwaltungsdirektorin a.D. Düsseldorf

\section{Verstorben}

\section{Margarete Deutsch}

\author{
Vorsitzende Richterin
} am Landesarbeitsgericht i.R., Düsseldorf

im 93. Lebensjahr

\section{Dorothee Langer}

Rechtsanwältin, Herborn

im 53. Lebensjahr 